\title{
MODIFICATION AND ANALYSES OF STRUCTURAL PROPERTIES OF A GOODS WAGON BOGIE FRAME
}

\author{
Ján DIŽO ${ }^{1}$, Miroslav BLATNICKÝ ${ }^{1}$, Jozef HARUŠINEC ${ }^{1}$, Anatoliy FALENDYSH ${ }^{2}$ \\ ${ }^{1}$ University of Žilina, Faculty of Mechanical engineering, Department of Transport and Handling Machnines, \\ Univerzitná 8215/1, 01026 Žilina, Slovak Republik, e-mail: jan.dizo@ fstroj.uniza.sk, \\ miroslav.blatnicky@fstroj.uniza.sk, jozef.harusinec@fstroj.uniza.sk \\ ${ }^{2}$ Ukrainian State University of Railway Transport, Faculty of Mechanics and Energy, Department of Heat \\ Engineering and Heat Engines, Feierbakh Square 7, 61050 Kharkov, Ukraine, e-mail: fap_hiit@ukr.net
}

Abstract

The contribution presents a modification of a goods wagon bogie frame. Every newly designed or significantly modified any support part of a railway bogie must meet strict criteria related to its strength and fatigue life. It presents key changes of the structure of an original goods wagon bogie frame, conditions and results strength analyses for unfavourable load cases, for which values of load forces come out from valid standards. The introductory part presents the original goods wagon bogie and the idea of its modification. In the next part analyses of structural properties (modal and stress analyses) are introduced. Simulation computations were carried out using Finite Element Method. Further, main load cases which all bogies must meet before commissioning and conditions for bogies approval are described. In simulation calculations a goods bogie frame was loaded in compliance with standards by four unfavourable load cases.

Keywords: goods wagon bogie, modified design, bogie frame, modal analysis, strength analysis

\section{INTRODUCTION}

The railway transport of goods represents an important element of a transport service. Given than it is an environmentally friendly kind of goods transport, its importance is seen in the inseparable part of the transport system in every developed country. The railway transport allows moving large quantities of goods over longer distance by the efficient way. Nowadays the design of rail vehicles meets conflict requirements. On one hand there is the rail vehicles weight reducing and the other hand all railway transport means must meet strict safety criteria. Every new designed railway vehicle and also construction units, e.g. bogies must satisfy the terms set out in codes before commissioning [6].

\section{MODIFICATION OF A GOODS WAGON BOGIE FRAME}

As not only in the region of the middle Europe (Slovak Republic, Czech Republic, Poland, Hungary etc.) the goods railway transport makes use of the same railway tracks as passenger railway transport, the question about the stronger depreciation of this infrastructure arises [16, 27]. These negative outcomes strongly relate among other things with the much higher axle load of freight wagons and different design of freight wagons bogies.

This different design does not allow the bogie to adapt to rugged track profiles mainly because of its stiff structure. Although there are solutions allowing steering wheelsets in curves by releasing the wheelsets in guidance, but on the other side, such a design meets problems when a freight wagon passes straight sections of tracks [7, 8, 22]. Therefore we present the current idea of a modification of an original goods wagon bogie.

The technical solution relates to the Y25 goods wagon bogie (Fig. 1). It is the most widely used bogie for goods wagon of various types, e.g. open goods wagon, flat wagon, hopper wagon, bolster wagon, tank wagon etc. It is equipped only with a single-stage suspension consists of duplex coil springs and the typical friction damper.

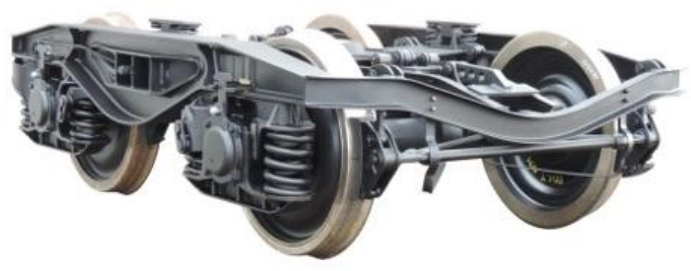

Fig. 1. Illustration of the original Y25 bogie design

The presented modification consists in structural changes of the main carrying part of the bogie, i.e. the bogie frame. By reason that such a modification significantly changes a structure of the frame, there is necessary to perform all analyses according to applicable regulations in order to ensure reliable operation throughout its lifetime. 
Views of the original and modified models of frames are shown in Fig. 2. Upon preliminary considerations we have acceded to the inherent structural modification of the bogie frame. It consists in several steps. Firstly we removed buffer beams (4). They substantially have served as brake bearers. In conjunction with it we have also removed brakes bearers (5) screwed in the middle part of the original bogie frame. As the modified bogie has not any longer main brakes bearers, a brake system must have also been modified (see below). In the next step the design of chassis members (2) had to be modified as well. They are shortened close to axle guards (3), main legs have different geometry and also upper hank ties enclosed by bends (Fig. 2). For guarantee of a sufficient structural strength of the modified frame thicknesses of some metal sheets of the main cross member (1) were increased in corresponding locations based on stress analyses (chapter 4)

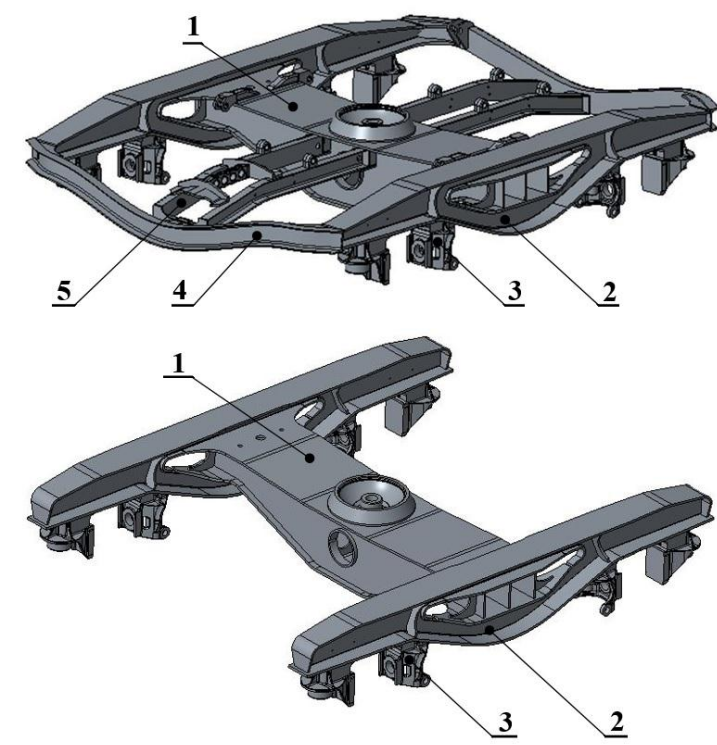

Fig. 2. Model of the original goods wagon bogie frame a) and the modified goods wagon bogie frame b): 1 - main cross member, 2 - chassis member, 3 - axle guards, 4 - buffer beams, 5 brakes bearers

By reason of the removing main bearer parts of a brake system, the original brake system has to be also modified.

Nowadays renowned producers of brake systems for railway vehicles offer such solutions, which allow to solve this problem sufficient effective. In principle there are two options.

Either an integrated block acting on the one side of wheel can be used instead of the conventional block brake acting on both side of a wheel or a goods bogie can be equipped with a disc brake.

Each of them has specific properties. Generally we can see, a single block brake is characterized by the lower weight, simple axle of a wheels, further a brake block ensures cleaning the wheel surface and last but not least by lower acquisition price. On the other hand, the operation of wagons exerting bogies with disc brakes is much less noisy, a lifetime of them is much longer, but in the contrast with the higher cost of acquisition and also higher weight, because such a brake requires axles equipped at least with two (or more) discs. Therefore, the final decision depends mainly on a customer requirements and preferences, which one has to be mounted on a bogie.

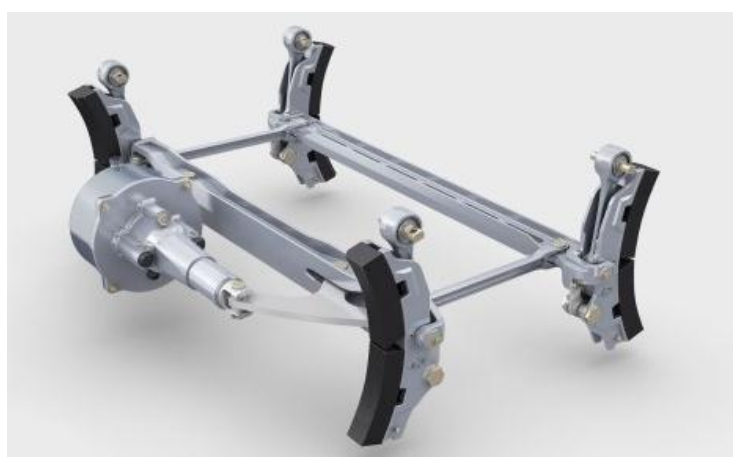

Fig. 3. Integrated block brake for goods wagons [10]

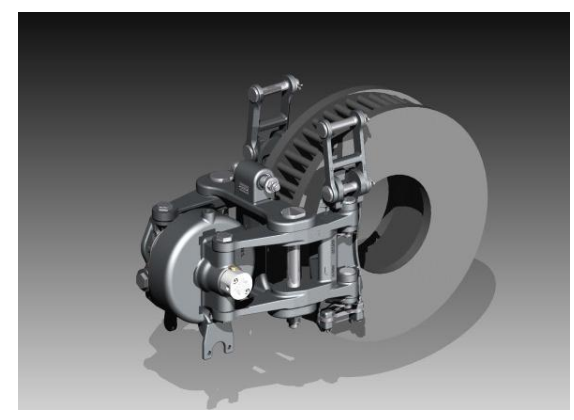

Fig. 4. Disc brake for goods wagons [9]

After design modification and virtual model creation there was possible to access to analyses of structural properties. We have aimed at analyses of modal properties as the base for dynamic properties investigation and at stress analyses under specified load conditions.

Modal properties calculations [1] and calculations of structural properties $[19,21]$, in which a construction is exposed to prescribed loads, are first step in the analysing of every newly designed wagon bogie unit $[5,23]$. All analyses we have carried out by means of Finite Element Method using Ansys software package [24, 26]. It allows engineers to create computer models of structures, machine components or whole systems, to apply operating loads and other design criteria and study physical responses [20, 25, 28], such as stress levels, pressure, deformations, etc.

\section{MODAL ANALYSIS OF GOODS WAGON BOGIE FRAMES}

The modal analysis solves characteristic oscillation of a frame structure [11, 17]. Then the matrix form of equations of motion describing this 
system with the proportional damping is known and follows:

$$
\boldsymbol{M} \cdot \ddot{\boldsymbol{u}}+\boldsymbol{K} \cdot \dot{\boldsymbol{u}}+\boldsymbol{C} \cdot \boldsymbol{u}=0
$$

where:

$M$ : a mass matrix,

$\boldsymbol{K}$ : a damping matrix

$C$ : a stiffness matrix,

$\ddot{\boldsymbol{u}}, \dot{\boldsymbol{u}}$ and $\boldsymbol{u}$ : vectors of nodes accelerations, velocities and displacements, respectively.

Modal analysis process includes several steps, which are needed to perform for successful computation. It can be described as follows:

- CAD model creation - preparing of the 3D model of a bogie frame, generation of an appropriate model files,

- setting up the FEM model,

- the model meshing by 8-nodes shell elements and 10-nodes quadratic tetrahedron elements.

In locations of shell and volume elements nodes connections so-called multi point constraints (MPC) contact elements for bonded connections were applied.

The frame is generally made of the combination of $\mathrm{S} 355 \mathrm{~J} 2+\mathrm{N}$ steel (sheet-steel parts of various thicknesses) and E300-520-MSC1 steel (centre pivot and axle guides), which yield strength is of $R_{y}^{355}=350 \mathrm{MPa} \quad \mathrm{MPa}$ and $R_{y}^{300}=300 \mathrm{MPa}$, respectively. Moreover, we have defined homogenous, isotropic, linear and elastic material model and mechanical properties corresponding to the Young's modulus of elasticity of $E=2.1 \cdot 10^{11} \mathrm{MPa}$ and Poisson's ratio of $\mu=0.3$.

As boundary conditions we have chosen the constraint of all degrees of freedom in the centre pivot. From modal analysis we have selected first six eigenmodes and eigenfrequencies. Figure 2 shows eigenmodes of the modified goods wagon bogie frame.

Values of eigenfrequencies and their comparison are introduced in Table 1.

Table 1. Comparison of eigenfrequencies of the original bogie frame and the modified bogie frame

\begin{tabular}{|r|r|r|}
\hline & Original design & Modified design \\
\hline Eigenmode & $\begin{array}{r}\text { Eigenfrequency } \\
{[\mathbf{H z}]}\end{array}$ & $\begin{array}{r}\text { Eigenfrequency } \\
{[\mathbf{H z}]}\end{array}$ \\
\hline $1^{\text {st }}$ mode & 29.72 & 35.37 \\
\hline $2^{\text {nd }}$ mode & 32.12 & 36.11 \\
\hline $3^{\text {rd }}$ mode & 35.46 & 38.18 \\
\hline $4^{\text {th }}$ model & 39.90 & 40.42 \\
\hline $5^{\text {th }}$ mode & 41.54 & 44.09 \\
\hline $6^{\text {th }}$ mode & 48.31 & 44.43 \\
\hline
\end{tabular}

Let's compare results of modal analyses of the original and modified bogie frame. We can observe, that the frequency difference is from $0.518 \mathrm{~Hz}\left(4^{\text {th }}\right.$ mode) to $5.655 \mathrm{~Hz}\left(1^{\text {st }}\right.$ mode $)$.
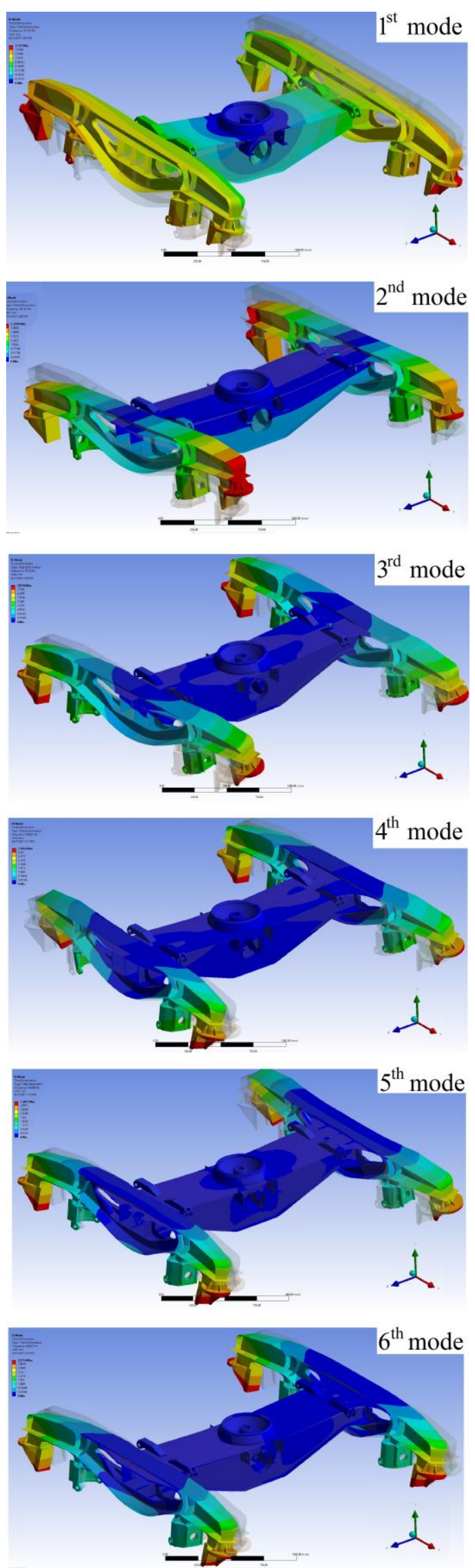

Fig. 5. Illustration of the first six eigenmodes of a modified goods wagon bogie frame 
Hence, from our analyses and calculations we can assume, modal properties of the modified bogie frame are similar to the original bogie frame and dynamic response caused various dynamic effects would be also similar.

\section{STRESS ANALYSES OF A MODIFIED GOODS WAGON BOGIE FRAME}

A real bogie and its frame are loaded in real operational conditions by a wide spectrum of loads which depend on actual level of loading, quality of a track expressed by variations form its geometric ideal position load or an eventual buckling of the track in the given track section and various other factors. This results in the variable operational load which is practically not possible to describe by load dependencies. Therefore, for the load of bogie frames the replacement load spectrum was determined according to which new developed bogies are tested. For this testing load bogie frames are designed and optimised in terms of strength and virtual tests. This testing load is intended in legislation, such as UIC edict, European and national norms [3,4] or internal directives of a vehicle operator [18].

Generally, various load cases of bogie frames can be divided into external and internal. For all categories in all applications the internal load is defined as well as the external load: exceptional load, which should not produce permanent deformation or excessive deflections and normal service loads, which should not induce fatigue cracks [3].

An analysed frame is the component of a freight wagon bogie. According to the standard, this bogie belongs to the category B-V namely Freight wagon bogies with a central pivot and two sidebearers. We have analysed this bogie frame in such way that we proceeded in accordance with the valid standard [3].

Before strength analyses there is necessary to calculate values of these load forces. We have performed it in compliance with formulations introduced in the mentioned standard [3]. Input quantities are:

- the total weight of the bogie $m=5.0 \mathrm{t}$,

- wheelbase $B=1.8 \mathrm{~m}$,

- the total weight of a freight wagon $m_{w}=90.0 \mathrm{t}$.

\subsection{Definition of the loads}

Calculations of bogie loads are introduced in the standard [3]. The bogie is loaded in the vertical direction by the force:

$$
F_{Z}=\left(\frac{m_{W}}{2}-m\right) \cdot g
$$

For the vertical direction the value of the exceptional load is given by these formulas:

- if vertical forces act only in the centre pivot:

$$
F_{Z P \max }=2 \cdot F_{Z}
$$

- if vertical forces act in the centre pivot and on the one sidebearer:

$$
\begin{gathered}
F_{Z 1 \max }\left(\text { or } F_{Z 2 \max }\right)=1.5 \cdot F_{Z} \cdot \alpha \\
F_{Z P}=1.5 \cdot F_{Z}(1-\alpha)
\end{gathered}
$$

where $F_{Z}$ is the total vertical load the a bogie, $F_{Z P}$ is the vertical force acts in the centre pivot, $F_{Z 1}$ and $F_{Z 2}$ are vertical forces act on sidebearers, $\alpha$ is coefficient for the body swinging. In our case we have considered with the value of $\alpha=0.3$.

For the lateral force of the exceptional load acting on the every wheelset there is applied following:

$$
F_{Y 1 \max }=F_{Y 2 \max }=\frac{F_{Y \max }}{2}=10^{4}+\frac{F_{Y}}{6}+\frac{\mathrm{m} \cdot \mathrm{g}}{6}
$$

The longitudinal force straining bogie frame is given:

$$
F_{X 1 \max }=0.1 \cdot\left(F_{Z}+m \cdot g\right)
$$

The load involved in case of the wagon impact is possible to substitute for the static longitudinal force acting in places, where the equipment is connected to the bogie. Its value is determined from the mass of individual elements and maximum acceleration acting on them during wagon impact $[14,15]$.

\subsection{Numerical calculations and results}

Process of computer analyses of a bogie frame includes several steps, which are needed to perform for successful calculation [2, 12]. We can it describe as follows:

- creation of a CAD model of the considered body, appropriate model files generation.

- setting up a FEM model in Ansys.

- model - generation of 8-nodes shell elements and 10-nodes quadratic tetrahedron elements (axle guides and centre pivot).

The bogie frame is generally made of combination S355J2+N and E300-520-MSC1 steels, which tensile strength $520-630 \mathrm{MPa}$ and 340 - $440 \mathrm{MPa}$, respectively. The S355 steel is used for the centre pivot and axle guides. Therefore, we have defined these parameters of material model:

- material was considered homogenous, isotropic, linear and elastic.

- mechanical properties - Young's modulus of elasticity $E=2.1 \cdot 1011 \mathrm{~Pa}$, Poisson's ratio $\mu=0.3$.

In this work we have focused on four most unfavourable load cases. They are determined by combinations of calculated loads, which act in bogie locations shown in Fig. 2 [3].

Combinations of loads are determined so that they represent maximal loads which would occur during operation of a rail vehicle. For freight wagon bogies with a central pivot and two sidebearers the standard consider combination of loads written in 
Table 3 , in which rows signs " $\checkmark$ " and " $\boldsymbol{x}$ ” express, if individual loads act or not, respectively.

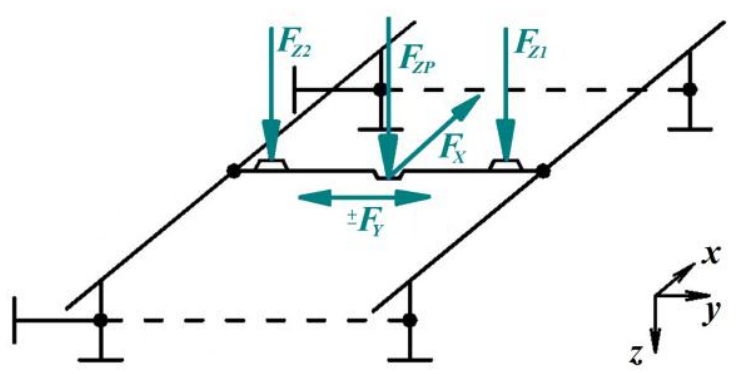

Fig. 6. Scheme of locations of loading forces

[3]

Next there are presented results from computer analyses of the modified bogie frame, which was subjected to four load cases corresponded to the exceptional load described in chapter 4.1.

Table 1 contains calculated data, which are needed to apply as loads on the bogie. The third column indicates, which formula from chapter 4.1 was used for calculation.

Table 2. Values of loading forces

\begin{tabular}{|r|r|r|}
\hline Force & Value [kN] & Equation \\
\hline$F_{Z}$ & 392.4 & 1 \\
\hline$F_{Z P \max }$ & 784.8 & 2 \\
\hline$F_{\text {ZImax }}$ & 176.58 & 3 \\
\hline$F_{Z P}$ & 412.02 & 4 \\
\hline$F_{Y I \max }$ & 83.575 & 5 \\
\hline$F_{\text {XImax }}$ & 44.145 & 6 \\
\hline
\end{tabular}

Table 3. Combinations of loading forces

\begin{tabular}{|r|r|r|r|r|r|}
\hline $\begin{array}{r}\text { Load } \\
\text { case }\end{array}$ & $\begin{array}{r}\boldsymbol{F}_{\text {ZPmax }} \\
{[\mathbf{k N}]}\end{array}$ & $\begin{array}{r}\boldsymbol{F}_{\text {ZImax }} \\
{[\mathbf{k N}]}\end{array}$ & $\begin{array}{r}\boldsymbol{F}_{\text {ZP }} \\
{[\mathbf{k N}]}\end{array}$ & $\begin{array}{r}\boldsymbol{F}_{\text {YImax }} \\
{[\mathbf{k N}]}\end{array}$ & $\begin{array}{r}\boldsymbol{F}_{\text {XImax }} \\
{[\mathbf{k N}]}\end{array}$ \\
\hline First & $\checkmark$ & $\mathbf{x}$ & $\mathbf{x}$ & $\mathbf{x}$ & $\mathbf{x}$ \\
\hline Second & $\mathbf{x}$ & $\checkmark$ & $\checkmark$ & $\mathbf{x}$ & $\mathbf{x}$ \\
\hline Third & $\mathbf{x}$ & $\checkmark$ & $\checkmark$ & $\checkmark$ & $\mathbf{x}$ \\
\hline Fourth & $\mathbf{x}$ & $\mathbf{x}$ & $\checkmark$ & $\checkmark$ & $\checkmark$ \\
\hline
\end{tabular}

The structure of a bogie frame is acceptable, when it withstands required loads without deflecting to an extent that would impair functionality under the application of the loads or without suffering permanent deformation after removal of the loads [3]. Unlike other standard engineering design and calculations, in which results of stress analyses are generally compared with a yield of strength within determined safety factor, the field of design of rail vehicles and their substructures, the safety factor of a designed structure is included in calculated loads. It practically means that calculated loads acting on an investigated structure are purposely greater in all load cases and stresses in whole structure have to be under a yield of strength.

Figures 4, 5, 6 and 7 show results from stress numerical analyses of the modified freight wagon bogie frame under four load cases in compliance with Tab. 3. We have evaluated stresses according to the HMH hypothesis.

The frame structure is satisfactory, if in all load cases evaluated stresses are less than the yield stress of the used material.

Let's look at Fig. 4. The first load case is the state when the highest value of the exceptional load acts on the frame $\left(F_{Z P \max }=784.8 \mathrm{kN}\right)$ only in the centre pivot.

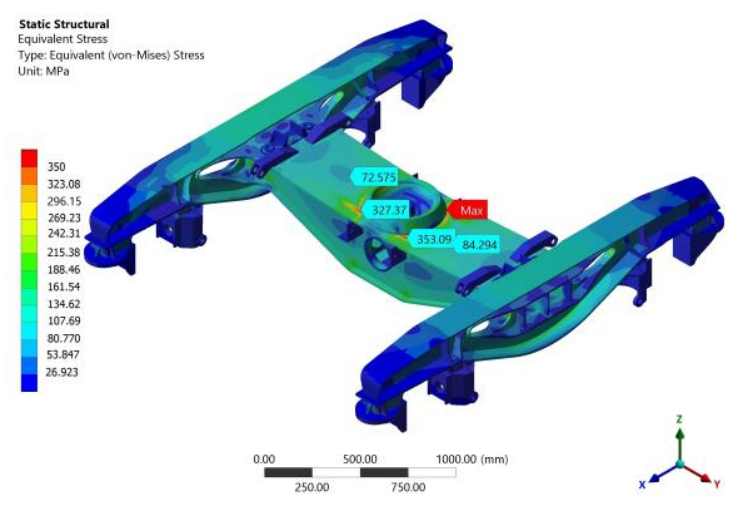

Fig. 7. Results of the stress analysis for the first load case

Under this load the highest values of the stress arise in the centre pivot region. The maximum is approx. $350 \mathrm{MPa}$. This would indicates, that the frame structure in this region is at the limit of acceptability, but we have to consider important facts. During analysing more variants of FE mesh size were used and compared. Based on results we have found out that this extreme value is obviously caused by calculation errors. Other values are lower and comply given limits.

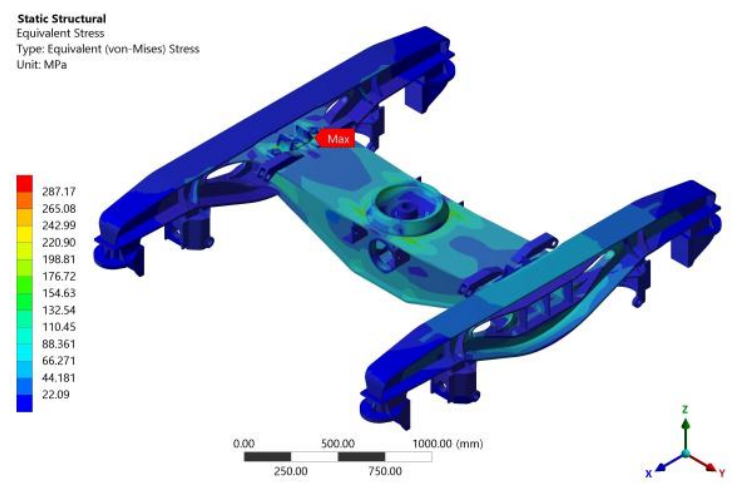

Fig. 8. Results of the stress analysis for the seconds load case

In the second exceptional load case the frame was loaded by forces acting in the centre pivot and on the one sidebearer $\left(F_{Z P}=412.02 \mathrm{kN}\right.$ and $\left.F_{Z 1 \max }=176.58 \mathrm{kN}\right)$ (Table 3$)$. Such a load mode simulates a wagon body swinging. From results shown in Fig. 5 we can see, that the maximum stress is in the loaded sidebearer area and it reaches value of $300.26 \mathrm{MPa}$. It is even safely below the yield stress of the used material. 


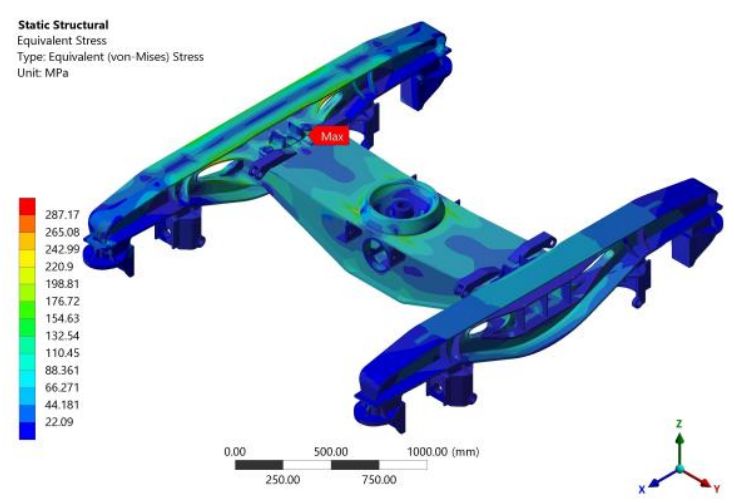

Fig. 9. Results of the stress analysis for the third load case

In the third load case the exceptional load is formed by two vertical forces $\left(F_{Z P}=412.02 \mathrm{kN}\right.$, $\left.F_{Z 1 \max }=176.58 \mathrm{kN}\right)$ and one lateral force $\left(F_{\text {Ylmax }}=83.575 \mathrm{kN}\right)($ Tab. 3$)$.

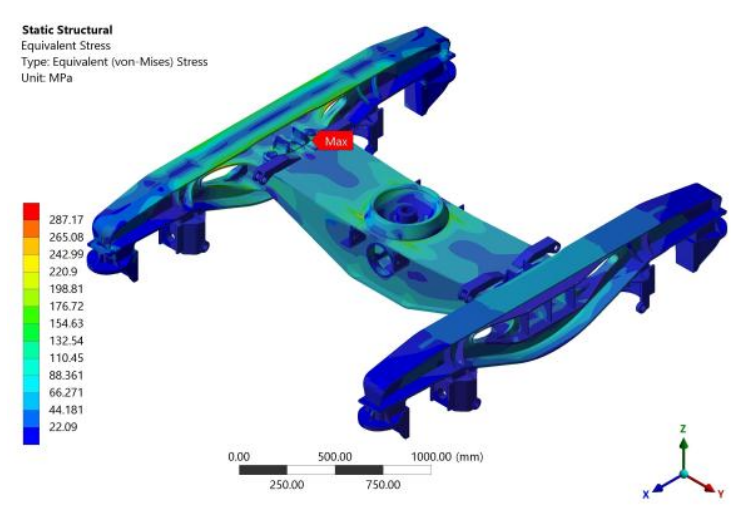

Fig. 10. Results of the stress analysis for the third load case

As we can see in Fig. 2, vertical forces act in the centre pivot and lateral force on the sidebearer. The maximum stress is similar to the second load case in the loaded sidebearer area (Fig. 6). The value of $304.61 \mathrm{MPa}$ is higher than in the previous load case, but still within permitted limits.

Finally, we evaluate the fourth most unfavourable load case. In comparison with the previous case, vertical loads are the same $\left(F_{Z P}=412.02 \mathrm{kN}, F_{Z 1 \max }=176.58 \mathrm{kN}\right)$. Instead of the lateral force, the longitudinal force acts in the centre pivot $\left(F_{X I \max }=44.145 \mathrm{kN}\right)$ (Table 3$)$. This force simulates the dynamic effects caused by traction and braking forces, etc. The maximum stress value (Fig. 4 right) is slightly higher in comparison with the third load case and that is 309.55 MPa. It is still well below the yield stress.

Based on performed analyses and evaluated results thicknesses of metal sheets of the main cross member were increased in those locations where detected stresses were close to the maximum permissible values.

\section{CONCLUSION}

In this work a modified freight wagon bogie were presented. Its design comes out from the standard Y25 freight wagon bogie. Every newly designed structure of any bogie has to be capable for operation. This capability is verified procedures introduced in relevant standards. Therefore we have chosen four load cases, which represent the most unfavourable load including exceptional load of a bogie. We have performed numerical analyses of the bogie frame structure and based on results we have found out that the structure meets requirements prescribed in the standard.

\section{SOURCE OF FUNDING}

The work was supported by the Cultural and Educational Grant Agency of the Ministry of Education of the Slovak Republic in the project No. KEGA 077ŽU-4/2017: Modernization of the Vehicles and engines study program.

The work was supported by the Slovak Research and Development Agency of the Ministry of Education, science, Research and Sport of the Slovak Republic in Educational Grant Agency of the Ministry of Education of the Slovak Republic in the project No. VEGA 1/5058/18: Research of the interaction of a braked railway wheelset and track in simulated operational conditions of a vehicle running in a track on the test bench.

\section{REFERENCES}

1. Baran P, Brezani M, Kukuca P, Stastniak P. Basic dynamical analysis and comparison of balancing systems of non-conventional piston machine FIK. Procedia Engineering 2017; 192, 34-39. https://doi.org/10.1016/j.proeng.2017.06.006.

2. Droppa P, Filipek S, Cornak S. The possibilities of using and simulation methods to design and modernization of military technics. $20^{\text {th }}$ International Conference Transport Means 2016, Juodkrante, Lithuania.

3. EN 13749, Railway Applications - Wheelsets and bogies - Method of specifying the structural requirements of bogie frames, European Committee for Standardization, Brussels, (2011).

4. Fabian P., Gerlici J., Masek J., Marton P. Versatile, efficient and long wagon for intermodal transport in Europe. Komunikacie 2013, 15(2), 118-123.

5. Gorbunov M, Gerlici J, Kara S, Nozhenko O, Chernyak G, Kravchenko K, Lack T. New principle schemes of freight cars bogies. Manufacturing Technology 2018; 18(2), 233-238. https://doi.org/10.21062/ujep/83.2018/a/12132489/MT/18/2/233.

6. Grencik J, Poprocky R, Gallikova J, Volna P. Use of risk assessment methods in maintenance for more reliable rolling stock. MATEC Web of Conference $2018 ; 157$.

https://doi.org/10.1051/matecconf/201815704002.

7. Hauser V, Nozhenko O, Kravchenko K, Loulova M, Gerlici J, Lack T. Impact of three axle boxes bogie to the tram behaviour when passing curved track. 
Procedia Engineering 2017; 192, 295-300. https://doi.org/10.1016/j.proeng.2017.06.051.

8. Hauser V, Nozhenko O, Kravchenko K, Loulova M, Gerlici J, Lack T. Proposal of a steering mechanism for tram bogie with three axle boxes. Procedia Engineering 2017; 192, 289-294. https://doi.org/10.1016/j.proeng.2017.06.050.

9. http://www.dako-cz.cz/en/disc-brake-unit-brake-disc.

10. http://www.knorr-bremse.de/en/press/pressreleases/ press_detail_33408.jsp.

11. Klimenda F, Soukup J. Modal analysis of thin aluminium plate. Procedia Engineering 2017; 177, 11-16. https://doi.org/10.1016/j.proeng.2017.02.176.

12. Lack T, Gerlici J. Modified strip method utilisation for wheel/rail contact stress evaluation. $9^{\text {th }}$ International Conference on Contact Mechanics and Wear of rail/Wheel Systems, CM 2012, Chengdu, China.

13. Lack T, Gerlici J. Y25 freight car bogie models properties analysis by means of computer simulations. MATEC Web of Conferences 2018; 157. https://doi.org/10.1051/matecconf/201815703014.

14. Leitner B. Discrete optimization of the rail vehicle frame weight with respect to fatigue damage cumulation process. $17^{\text {th }}$ International Conference Transport Means 2013, Kaunas, Lithuania.

15. Leitner B, Vasko M. Design and modelling of tank assembly operations in CAM environment. $19^{\text {th }}$ International Conference Transport Means 2015, Kaunas, Lithuania.

16. Masek J, Kendra M, Milinkovic S, Veskovic S, Barta D. Proposal and application of methodology of revitalisation of regional railway track in Slovakia and Serbia. Part 1: Theoretical approach and proposal of methodology for revitalisation of regional railways. Transport Problems 2015; 10, 85-95.

17. Melnik R, Sowinski B. The analysis of rail vehicle model eigenvalues for suspension fault detection method. $14^{\text {th }}$ Mini Conference on Vehicle System Dynamics, Identification and Anomalies, VSDIA 2014, Budapest, Hungary.

18. Nader M, Kostrzewski A, Kostrzewski M. Tehnological conditions of intermodal transhipment terminals in Polad. Archives of Transport 2017; 41(1), 73-88. https://doi.org/10.5604/01.3001.0009.7388.

19. Sapietova A, Saga M, Stancekova D, Sapieta M. Contribution to numerical study of vehicle vertical stochastic vibration. MATEC Web of Conferences $2018 ; 157$. https://doi.org/10.1051/matecconf/201815703015

20. Smetanka L, Gerlici J, Lack T, Pelagic Z. Homogenization of fibers reinforced composite materials for simulation analysis. Manufacturing Technology 2015; 15(5): 914-920.

21. Soukup J, Skocilasova B, Skocilas J. Vibration of mechanical system with higher degrees of freedom: Solution of the Frequency Equations. Procedia Engineering 2017; 177, 17-24. https://doi.org/10.1016/j.proeng.2017.02.177.

22. Stastniak P, Moravcik M. Freight bogie prototype properties analysis by means of simulation computations. Manufacturing Technology 2017; 17(3), 381-388.

23. Steisunas S, Bureika G. Study of freight wagon running dynamic stability taking into account the track stiffness variation. Transport Problems 2014; 9(4), 131-143.
24. Suchanek A, Harusinec J. The downhill braked railway wheel structural analysis by means of the ANSYS Multiphysics program system package. Manufacturing Technology 2015; 15(5), 945-950.

25. Suchanek A., Harusinec J, Loulova M, Strazovec P. Analysis of the distribution of temperature fields in the braked railway wheel. MATEC Web of Conferences 2018; 157. https://doi.org/10.1051/matecconf/201815702048.

26. Svovoda M, Soukup J, Petrenko A. Use of FEM programs in solving general unbalance simple mechanical system of rigid, flexible stored bodies. $52^{\text {nd }}$ International Conference on Experimental Stress Analysis, EAN 2014, Marianske Lazne, Czech Republic.

27. Vaicunas G, Bureika G, Steisunas S. Reserch on metal fatigue of rail vehicle wheel considering the wear intensity of rolling surface. Eksploatacja I Niezawodnosc. 2018; 20(1), 24-29.

https://doi.org/10.17531/ein.2018.1.4.

28. Zvolensky P, Kasiar L, Volna P, Barta D. Simulated computation of the acoustic energy transfer through the structure of porous media in application of passenger carriage. Procedia Engineering 2017; 187, 100-109. https://doi.org/10.1016/j.proeng.2017.04.355 .

\section{Received 2018-06-08}

Accepted 2018-11-19

Available online 2018-11-26

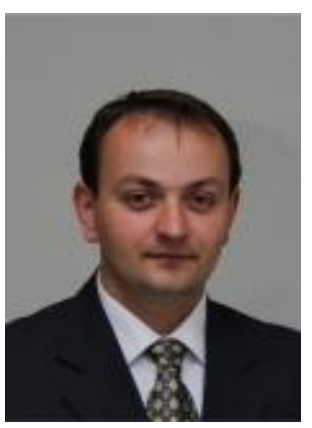

Ing. Ján DIŽO, PhD. received B.Sc., M.Sc. and PhD. degrees in Mechanical Engineering from University of Žilina, respectively. $\mathrm{He}$ is currently teaching at the Faculty of Mechanical Engineering, University of Žilina. Mr. Dižo's research interest mainly focuses on creation of MBS models and analysing dynamic structural properties of transport and handling machines.

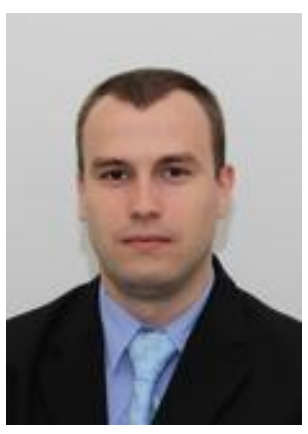

Ing. Miroslav BLATNICKÝ, $\mathrm{PhD}$. received M.Sc. and $\mathrm{PhD}$. degrees in Mechanical Engineering from University of Žilina, respectively. $\mathrm{He}$ is currently teaching at the Faculty of Mechanical Engineering, University of Žilina. His area of research is focused on functional and strength calculations and FEM analyses in the field of transport and handling machines, hoisting machinery and steel structures.

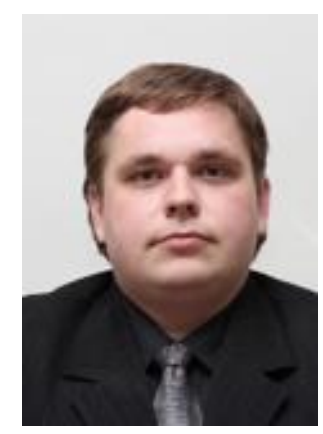

Ing. Jozef HARUŠINEC, PhD. received M.Sc. and PhD. Degrees in Mechanical Engineering from University of Žilina. He currently works at the Faculty of Mechanical Engineering and he is focused on the creation of virtual models of machines and equipment, technical calculations in engineering, simulation analyses in the field of a wheel/rail contact (strength and dynamic calculations and thermal phenomena analysing in a braked railway wheel). 


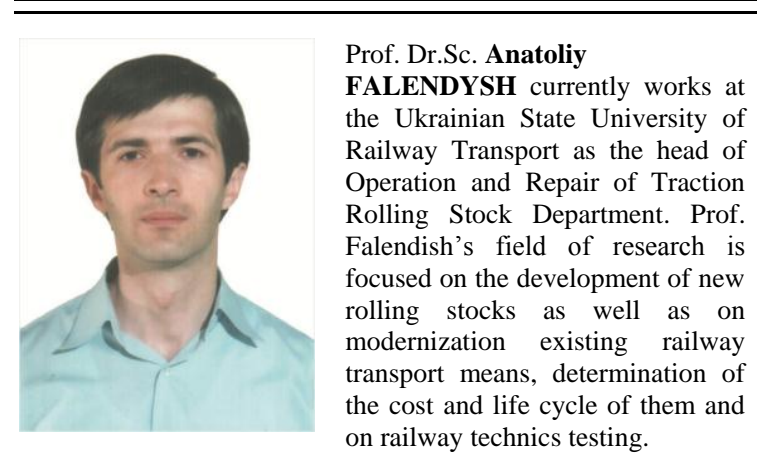

